1 Running head: Yellowjacket queen dispersal.

2 Title for authors: M. Masciocchi et al.

3 Corresponding author: Maité Masciocchi, CONICET. CCT Comahue (8400) Bariloche, Argentina; Tel: +54(0)294 4422731; email: masciocchi.maite@inta.gob.ar, maimasciocchi@gmail.com,

\title{
Dispersal behavior of yellowjacket (Vespula germanica) queens
}

Maité Masciocchi ${ }^{1,2}$, Andrés S. Martinez ${ }^{1,2}$, Ana J. Pereira ${ }^{1,2}$, José M. Villacide ${ }^{2}$ and Juan C. Corley ${ }^{1,2,3}$.

${ }^{1}$ CONICET. CCT Comahue (8400) Bariloche, Argentina, ${ }^{2}$ INTA. Grupo de Ecología de Poblaciones de Insectos, INTA EEA Bariloche, (8400) Bariloche, Argentina, and ${ }^{3}$ Centro Regional Universitario Bariloche, U. N. del Comahue, (8400) Bariloche, Argentina.

\section{Abstract}

Understanding the factors that affect animal dispersal behavior is important from both fundamental and applied perspectives. Dispersal can have clear evolutionary and ecological consequences, but for non-native insect pests, dispersal capacity can also help to explain invasion success. Vespula germanica is a social wasp that in the last century has successfully invaded several regions of the world, showing one of the highest spread rates reported for a non-native insect. In contrast with non-social wasps, in social species, queens are responsible for population re-distribution and spread, as workers are sterile. For V. germanica, it has been observed that queen flight is limited to two distinct periods: early autumn, when new queens leave the nest to mate and find sheltered places in which to hibernate, and spring when new colonies are founded. Our aim was to study the flight behavior of $V$. germanica queens, by focusing on the different periods in which dispersal occurs, characterizing as well the potential contribution of queen flight (i.e., distance) to the observed geographical spread. Our results suggest that the distances flown by non-overwintered queens is greater than that flown by overwintered individuals, suggesting that the main queen dispersal events would occur before queens enter hibernation. This could relate to a behavioral trait of the queens to avoid the inbreeding with related drones. Additionally given the short distances flown and remarkable geographical spread observed, we provide evidence showing that queen dispersal by flight is likely to contribute proportionately less to population spread than human-aided factors.

31 Key words: flight potential; German wasps; invasive wasps; hibernation; social insect

This is an Accepted Article that has been peer-reviewed and approved for publication in the Insect Science but has yet to undergo copy-editing and proof correction. Please cite this article as doi: 10.1111/1744-7917.12374.

This article is protected by copyright. All rights reserved. 


\section{Introduction}

Insect dispersal can have evolutionary, ecological and economic consequences, since it is the main mechanism leading to gene flow within and between populations and contributes to population spatio-temporal dynamics (Clobert et al., 2001; Bowler \& Benton, 2005; Nathan et al., 2008). Individual movement may affect population spatial structure and geographical distribution; for invasive species, dispersal can explain the rate of spread into new areas (Liebhold et al., 1995; Lavandero et al., 2004). This is likely why there is a growing interest in understanding dispersal behavior and flight capability of invasive insect species (Hasting et al., 2005; Gilbert \& Liebhold, 2010; Bigsby et al., 2011; Helms \& Kaspari, 2015).

It is widely recognized that invasive species disperse following two distinct processes (Shigesada \& Kawasaki, 1997). On one hand, short-range dispersal is largely explained by population growth added to the intrinsic dispersal capabilities of the species. On the other, migratory movements coupled with dispersal capacity, wind drift and anthropogenic movement contribute to long-range dispersal (Liebhold \& Tobin, 2008). The combination of both types of movement explains much of the observed spread of invasive insects (Shigesada \& Kawasaki, 1997). A well-studied emblematic example of this type of spread is that of the invasive gypsy moth (Lymantria dispar) in North America. The first instar larvae spread short-distances via silk threads and ballooning, while long distance dispersal is human-aided given that females cannot fly. In north America, both events explain an average rate of spread of $29 \mathrm{~km} /$ year (Liebhold et al., 1992; Johnson et al., 2006; Ascunce et al., 2011).

Added to its fundamental interest, understanding the dispersal capability of invasive pests and unravelling the factors regulating movement of individuals is important to help develop appropriate management programs. For those insects that rely on flight to move, factors such as body size and weight, wing span, mating status and sex can affect when and how far individuals disperse (Elliott \& Evenden, 2009). For example, the females of woodwasp Sirex noctilio, an invasive forest insect, display a highly variable flight capability and behavior related to the wasp mass (Bruzzone et al., 2009). In turn, the acceleration capacity in the butterfly Pararge aegeria has been shown to be related to several morphological characteristics such as total body mass and wing loading among others (Berwaerts et al., 2002).

Vespula germanica (Fabricius) (Hymenoptera: Vespidae) is an invasive eu-social vespid native to the Paleartic region. In the last century it has invaded New Zealand, Australia, South Africa, North America, Canada, Chile and Argentina (Beggs et al., 2011). Wasps have been shown to negatively affect natural ecosystems, economic and human recreational activities. For instance, the painful sting may interfere with human outdoor activities and affect residential areas where wasps are attracted to food and refuse (Akre \& MacDonald, 1986, Beggs et al., 2011). Since its first detection in Argentina in 1980, the species has dramatically increased its geographical distribution, covering almost the entire southern region of Argentina. In turn, $V$. germanica show a spread rate of $37 \mathrm{~km} /$ year, being the highest known for invasive social Hymenoptera (Masciocchi \& Corley, 2013). The overwintering of mated queens in human goods, their remarkable behavioral plasticity (e.g., an 
opportunistic foraging and nesting behavior) and their close association with human settlements have been suggested to be key drivers of the invasion success of this wasp (Beggs, 2001, Beggs et al., 2011, Masciocchi \& Corley, 2013).

As for all highly eu-social insects, Vespula germanica queens are the only reproductively active females and, as such are responsible for the spread of the population and the establishment of new colonies (Spradbery, 1973). Flight activity of queens outside the nest is limited in time, but contributes to the increase in population spatial redistribution, although accidental transport of overwintering queens is a well-known factor of geographical spread. In temperate regions, flight by queens occurs twice a year: in early autumn, when new queens leave the parental nest to mate and find shelter to overwinter and in spring, when new colonies are initiated by them. During diapause, $V$. germanica wasps decrease their metabolic rate and oxygen consumption to almost basal levels, but still lose up to $30 \%$ of their reserves which can only be regained only after diapause ends (Spradbery, 1973).

Here, we studied the flight behavior of $V$. germanica queens under laboratory conditions, focusing on the two periods in which dispersal occurs: prior to overwintering and after overwintering. We also explored the potential contribution of queen flight to the geographical spread observed by this wasp in Argentina. Our hypothesis is that $V$. germanica queens should disperse after overwintering given that the diapause induction and duration is facultative, and winter duration is unpredictable. Since winter duration is uncertain, it could be advantageous for queens to manage capital resources -those obtained during the larval stage- to succeed through hibernation and allow for subsequent dispersal before they can feed and start a nest. We expect queens to disperse more after they have successfully overwintered and are in possession of capital resources. Because $V$. germanica wasps are a major urban pest in the invaded range and that queens are responsible for population growth and spread, understanding their flight behavior and capacity may help us to improve the development of local and regional management strategies. Currently, the control of this species, in the most of invaded areas, is focused on the decrease of the local abundance of individuals, and no techniques are used to slow the spread of this species.

\section{Methods}

\section{Flight mill assays}

To measure accumulated flight distance $(\mathrm{m})$ we studied tethered females in a set of flight mills. Flight mills have been used in several studies to examine comparatively the effects of sex, age and physical parameters on flight performance (Cooter \& Armes, 1993; Moriya, 1995; Schumacher et al., 1997; Krell et al., 2003; Villacide \& Corley, 2008; Bruzzone et al., 2009). A set of flight mills based on the model of Schumacher et al. (1997) were used in this study. Our flight trials were performed under controlled laboratory conditions, with light emitting diode (LED) illumination (700 Lm), controlled temperature $\left(21 \pm 2{ }^{\circ} \mathrm{C}\right)$ and humidity $(41 \% \pm 5 \% \mathrm{RH})$.

Vespula germanica queens used in the flight mill tests were obtained by excavating 10 live nests in the area of San Carlos de Bariloche (Argentina, $41^{\circ} 08^{\prime} \mathrm{S}$ and $71^{\circ} 18^{\prime} \mathrm{W}$ ) during the time new

This article is protected by copyright. All rights reserved. 
queens emerge from nests (i.e., April 2014). Nests were transported in containers to the laboratory where they were placed at $-10{ }^{\circ} \mathrm{C}$ for 10 minutes to anesthetize wasps. Adult queens were collected from the nests (a mean of $20 \pm 4$ queens per nest) and placed in individual containers. A group of queens $(n=44)$ were then tethered individually in flight mills, and a second, larger group $(n=116)$ was artificially induced to overwinter (see below).

It important to note that since the capacity of mated and unmated queens is comparable in terms of overwintering survival and nest beginning (Ross, 1983; Goodisman et al., 2002), we did not take into account the mating status in this study, even though it has been shown to be important for other insect species (Hughes \& Dorn, 2002; Elliott \& Evenden, 2009).

\section{Flight assays of non-overwintered queens}

Immediately after removing queens from the nests, they were placed in individual translucent plastic containers (diameter: $8 \mathrm{~cm}$, height: $4 \mathrm{~cm}$ ) and fed ad libitum with $1.8 \mathrm{~mol} / \mathrm{L}$ sugar solution during $24 \mathrm{~h}$ at $21 \pm 2{ }^{\circ} \mathrm{C}, 41 \% \pm 2 \% \mathrm{RH}$ in order to standardize feeding state (after $24 \mathrm{~h}$ of $\mathrm{ad}$ libitum feeding, queen weight does not increase further - total period measured $36 \mathrm{~h}$, Masciocchi pers. obs.). After feeding, queens were individually tethered to the flight mills. In order to do so, queens were anesthetized by exposing them for $20 \mathrm{~s}$ to a flow $(0.5 \mathrm{~L} / \mathrm{min})$ of $\mathrm{CO}_{2}$. While anesthetized, the head of an entomological pin was glued to the thorax with cyanoacrylate glue (La Gotita ${ }^{\circledR}$ ). Flight distance was recorded for $24 \mathrm{~h}$. After this period, all wasps were alive and the pin was carefully removed ensuring no traces of glue were left on the thorax. The weight before and after flight (initial weight, IW and final weight, FW respectively), the total wing area (TWA) and wasp head width $(\mathrm{HW})$ were recorded. The head width $(\mathrm{mm})$ was measured using a digital caliper, and the total wing area $\left(\mathrm{mm}^{2}\right)$ was measured by scanning all wings (resolution $600 \mathrm{dpi}$ ) and calculating the surface with the aid of specialized software (see Schneider, 2012).

\section{Flight assays of overwintered queens}

Queens induced to overwinter were placed in individual translucent plastic containers (diameter: $8 \mathrm{~cm}$, height: $4 \mathrm{~cm}$ ) and fed ad libitum ( $1.8 \mathrm{~mol} / \mathrm{L}$ sugar solution for $24 \mathrm{~h}$ ). Fed queens were placed in an incubator with a controlled light (8:16 light: dark regime), temperature $\left(9^{\circ} \mathrm{C}\right.$ during light hours $/ 5^{\circ} \mathrm{C}$ during dark hours) and humidity $(60 \% \pm 5 \% \mathrm{RH})$ regimes to induce diapause. Wasps were left under these conditions for 12 weeks. The criteria used to end diapause was the following: after 4 weeks of diapause the weight of 20 queens was monitored weekly, until the recorded average loss weight was 30\% (Spradbery, 1973). After diapause, wasps were removed from the incubator, fed ( $1.8 \mathrm{~mol} / \mathrm{L}$ sugar solution for $24 \mathrm{~h}$ ), anesthetized and subjected to the flight assays as described above. All parameters measured on overwintered queens were the same as previously described.

\section{Statistical analysis}

We used generalized linear models to analyze the effects of overwintering on queen flight behavior. The total distance flown was considered as a response variable, and the following factors as explanatory variables: diapause status ( $D$, with two levels: non-overwintered and overwintered), initial weight, head width and total wing area. Two-way interactions were evaluated in addition to 
single-variable effects. The exponential distribution was assumed for the response variable error structure. A backward manual iteration procedure was used to remove non-significant interactions and factors due to AIC criteria. Model comparisons were computed using the standard likelihood method (AIC). Residuals were examined to confirm that the final model accurately fitted the data. Additionally, a Paired $t$-test was used to compare the explanatory variables (head with, total wing area and initial weight) and distances in overwintered and non-overwintered queens. All analyses were performed using the R statistical environment (R Development Core Team, 2014).

\section{Results}

A total of 160 Vespula germanica queens were obtained from the excavated nests. Forty four nonoverwintered queens were flown in mills while 116 queens were induced to overwinter of which 35 survived and were subjected to the flight assays. Mortality rates are in line with those observed in natural conditions (Archer, 1984).

Significant differences were found between the distances flown by queens according to whether they had undergone induced diapause. Non-overwintered queens recorded a higher potential flight, dispersing $3 \mathrm{~km}$ farther than those that had overwintered (Table 1, Fig. 1). No significant differences were found when comparing head width nor total wing area between overwintering status. The weights prior to the flight assay were significantly higher for nonoverwintered queens (Table 1).

Flight distance is affected by the interaction between diapause status with the initial weight and diapause status with total wing area (final model: distance $~ D+T W A+I W+D: T W A+D: I W$; Table 2). For a best visualization of results, we present graphs of flight distance with individual predictors. The effect of the initial weight on distance flown is stronger in non-overwintered queens (Fig. 2A). In turn, the effect of wing area on distance flown is related to overwintering status; in queens that have not overwintered the flight distance decreased when the wing area increased, however the flight distance increased with increased wing area in overwintering queens (Fig. 2B, Table 2).

\section{Discussion}

This study is the first to quantify the dispersal behavior of $V$. germanica queens, a species that has become a major urban pest in many regions of the world. Contrary to our expectations, results indicate that queens fly more before overwintering. Additionally, we note that body weight prior to flight and wing area, both affect the distance flown, but that these effects depend on whether wasps have overwintered. As expected, the morphological features measured in this study, head width and total wing area, do not change with overwintering status.

In social insects, flight is central to reproduction and dispersal. It has been suggested that for ants, for example, queens experience a reproduction-dispersal trade-off that determines nutrient acquisition and storage patterns and ultimately body size (the Found of Fly hypothesis; Helms \& Kaspari, 2014). Larger queens have a higher chance of success during colony initiation but must bear 
a large drag and exposure to predation during flight leading to the evolution of flightlessness in many ant species (Holldobler \& Wilson, 1990; Helms \& Kaspari, 2015).

For Vespula spp. wasps, queen differences in weight before and after overwintering are a consequence resource use during the diapause process. During this time, wasps do not feed and decrease their metabolic rate and oxygen consumption, relying entirely on capital reserves (Bodine \& Evans, 1932). This implies that a decrease in their weight during winter is expected, which may be regained once the queen ends diapause (Spradbery, 1973). Mature adult queens which leave the nest in search of overwintering sites, have about $40 \%$ of their dry weight in the form of fat, obtained while larvae, in the parental nest. After diapause, queen weight can be reduced up to $30 \%$ although this loss can be compensated later, through feeding (Spradbery, 1963, 1973).

Flight mill trials showed that overwintered queens, although fed ad libitum prior to the assays, flew a third of the distance compared to non-overwintered individuals, suggesting that the major contribution to $V$. germanica dispersal occurs prior to overwintering. These differences between pre- and post-overwintered flights could be reflecting a queen behavioral trait where energetic resources are not the main driver. Dispersal before diapause could be favored instead by mating behavior. Previous studies on Vespula spp. have found that queens mate away from the nest, and that the queens produce a sex pheromone to attract males (Goodisman et al., 2002; Brown et al., 2013). Thus, we suggest that by flying further away from the nest, queens can reduce the chances of mating with sibling drones and furthermore, minimize competition with queen sisters for males (Strassmann, 2001). Conversely, shorter flights are made by overwintered queens probably reflecting a searching behavior for appropriate nesting sites in the immediacy of the overwintering shelters.

The distance flown by $V$. germanica queens was mainly affected by whether they had undergone overwintering, but also by their weight prior to flight and to their wing area. Before overwintering, queens have higher reserve levels and thus weigh more. Additionally, even though the wing area is not different between the queens studied here, the lower initial weight of overwintered queens, results in a lower wing loading, having in turn a positive effect on the distance flown. Conversely, we observed that the distance flown by the heavier, non-overwintered queens, is not affected by wing area, probably due to their larger wing loading.

In contrast with other invasive wasps, $V$. germanica has a relatively low dispersal capability. For example, similar flight mill studies have shown that females of the wood boring wasp Sirex noctilio can reach up to $50 \mathrm{~km}$ in one day (Bruzzone et al. 2009) a distance that matches invasion spread rates (Villacide \& Corley, 2012; Villacide et al., 2014). Although flight mill assays do not necessarily express how much insects fly in field conditions, our findings suggest that $V$. germanica may have a relatively low intrinsic dispersal capability, and other factors, such as the transport of overwintering queens in human goods such as timber, are likely important components of geographical spread (Crosland, 1991; Spradbery \& Maywald, 1992). 
In sum, our study indicates that $V$. germanica queens fly longer distances before overwintering. The higher dispersal capacity before wintering could be a behavioral trait selected to avoid inbreeding while suggesting that the energetic resources are not limiting. Moreover, queen dispersal capability appear to be relatively small compared to human-aided spread, suggesting that the implementation of sound management strategies that prevent human transport of reproductives could be important in slowing the spread of $V$. germanica populations in invaded areas.

\section{Acknowledgments}

This study was financed by a grant from Consejo Nacional de Investigaciones Científicas y Técnicas, PIP 2010, Grant \# 11220090100043 and PICT-2013-0527 of Agencia Nacional de Promoción Científica y Tecnológica. Ana J. Pereira is PhD student of CONICET; José Villacide is INTA Research Fellow, Maité Masciocchi, Andrés Martinez and Juan C. Corley are CONICET Research Fellows. We thank Deborah Fischbein who provided helpful comments to early versions of the manuscript.

\section{Disclosure}

The authors declare no conflicts of interest.

\section{References}

Akre, R.D. and MacDonald, J.F. (1986) Biology, economic importance and control of yellowjackets. Economic Impact and Control of Social Insects. (ed. by Vinson, S. B.), Praeger, New York, 421 pp.

Archer, M. (1984). Life and fertility tables for the wasp species Vespula vulgaris and Dolichovespula sylvestris (Hymenoptera: Vespidae) in England. Entomologia Generalis, 9,181-188.

Ascunce, M.S., Yang, C.C., Oakey, J., Calcaterra, L., Wu, W.J., Shih, C.J., Goudet, J., Ross, K.G. and Shoemaker, D.W. (2011) Global invasion history of the fire ant Solenopsis invicta. Science, 331,1066-1068.

Beggs, J.R. (2001) The ecological consequences of social wasps (Vespula spp.) invading an ecosystem that has an abundant carbohydrate resource. Biological Conservation, 99,17-28.

Beggs, J.R., Brockerhoff, E.G., Corley, J.C., Kenis, M., Masciocchi, M., Frank, M., Quentin, R. and Villemant, C. (2011) Ecological effects and management of invasive alien Vespidae. BioControl, 56,505-526.

Berwaerts, K., van Dyck, H. and Aerts, P. (2002) Does flight morphology relate to flight performance? An experimental test with the butterfly Pararge aegeria. Functional Ecology, 16,484-491.

Bigsby, K.M., Tobin, P.C. and Sills, E.O. (2011) Anthropogenic drivers of gypsy moth spread. Biological Invasions, 13,2077-2090.

This article is protected by copyright. All rights reserved. 
Brown, R.L., El-Sayed, A.M., Suckling, D.M., Stringer, L.D. and Beggs, J.R. (2013) Vespula vulgaris (Hymenoptera: Vespidae) gynes use a sex pheromone to attract males. Canadian Entomology, 145,1-9.

Bruzzone, O.A., Villacide, J.M., Bernstein, C. and Corley, J.C. (2009) Flight variability in the woodwasp Sirex noctilio (Hymenoptera: Siricidae): an analysis of flight data using wavelets. Journal of Experimental Biology, 212,731-737.

Clobert, J., Danchin, E., Dhondt, A.A. and Nichols, J.D. (2001) Dispersal. Oxford University Press, Oxford.

Cooter, R. and Armes, N. (1993) Tethered flight technique for monitoring the flight performance of Helicoverpa armigera (Lepidoptera: Noctuidae). Environmental Entomology, 22,339-345.

Crosland, M.W.J. (1991) The spread of the social wasp, Vespula germanica, in Australia. New Zealand Journal of Zoology, 18, 375-388.

Elliott, C.G. and Evenden, M.L. (2009) Factors influencing flight potential of Choristoneura conflictana. Physiological Entomology, 34, 71-78.

Gilbert, M. and Liebhold, A. (2010) Comparing methods for measuring the rate of spread of invading populations. Ecography, 33, 809-817.

Goodisman, M.A.D., Matthews, R.W. and Crozier, R.H. (2002) Mating and reproduction in the wasp Vespula germanica. Behavioral Ecology and Sociobiology, 51,497-502.

Hasting, A., Cuddington, K., Davies, K.F., Dugaw, C.J., Elmendorf, S., Freestone, A., Harrison, S., Holland, M., Lambrinos, J. and Malvadkar, U. et al. (2005) The spatial spread of invasions: new developments in theory and evidence. Ecological Letters, 8, 91-101.

Helms, J.A. and Kaspari, M. (2014) Found or fly: nutrient loading of dispersing ant queens decreases metrics of flight ability (Hymenoptera: Formicidae). Myrmecolical News, 19,85-91.

Helms, J.A. and Kaspari, M. (2015) Reproduction-dispersal trade-offs in ant queens. Insectes Sociaux, $62,171-181$.

Hölldobler, B. and Wilson, E.O. (1990) The Ants. Belknap Press of Harvard University Press, Cambridge, MA.

Hughes, J. and Dorn, S. (2002) Sexual differences in the flight performance of the oriental fruit moth, Cydia molesta. Entomologia Experimentalis et Applicata, 103,171-182.

Johnson, D.M., Liebhold, A.M., Tobin, P.C. and Bjernstad, O.N. (2006) Allee effects and pulsed invasion by the gypsy moth. Nature, 444, 361-363.

Krell, R.K., Wilson, T.A., Pedigo, L.P. and Rice, M.E. (2003) Characterization of bean leaf beetle (Coleoptera: Chrysomelidae) flight capacity. Journal of the Kansas Entomological Society, $76,406-416$. 
Lavandero, B., Wratten, S., Hagler. J. and Jervis, M. (2004) The need for effective marking and tracking techniques for monitoring the movements of insect predators and parasitoids. International Journal of Pest Management, 50,147-151.

Liebhold, A.M., Halverson, J.A. and Elmes, G.A. (1992) Gypsy moth invasion in North America: a quantitative analysis. Journal of Biogeography, 19,513-520.

Liebhold, A.M., MacDonald, W.L., Bergdahl, D. and Mastro, V.C. (1995) Invasion by exotic forest pests: a threat to forest ecosystems. Forest Science, 41, a0001-z0001.

Liebhold, A.M. and Tobin, P.C. (2008) Population ecology of insect invasions and their management. Annual Review of Entomology, 53,387-408.

Masciocchi, M. and Corley, J.C. (2013) Distribution, dispersal and spread of the invasive social wasp (Vespula germanica) in Argentina. Austral Ecology, 38,162-168.

Moriya, S. (1995) A preliminary study of the flight ability of the sweetpotato weevil, Cylas formicarius (Fabricius) (Coleoptera: Apionidae) using a flight mill. Applied Entomology and Zoology, 30,244-246.

Nathan, R., Getz, W.M., Revilla, E., Holyoak, M., Kadmon, R., Saltz, D. and Smouse, P.E. (2008) A movement ecology paradigm for unifying organismal movement research. Proceedings of the National Academy of Sciences of the United States of America, 105,19052-19059

R Development Core Team (2014) R Foundation for Statistical Computing. R: A Language and Environment for Statistical Computing.

Ross, K.G. (1983) Laboratory studies of the mating biology of the eastern yellowjacket, Vespula maculifrons (Hymenoptera: Vespidae). Journal of the Kansas Entomological Society, 56,523537.

Schneider, C.A., Rasband, W.S. and Eliceiri, K.W. (2012) NIH Image to ImageJ: 25 years of image analysis. Nature Methods, 9,671-675.

Shigesada, N. and Kawasaki, K. (1997) Biological Invasions: Theory and Practice. USA, Oxford University Press.

Schumacher, P., Weyeneth, A., Weber, D.C. and Dorn, S. (1997) Long flights in Cydia pomonella L. (Lepidoptera: Tortricidae) measured by a flight mill: Influence of sex, mated status and age. Physiological Entomology, 22,149-160.

Spradbery, J.P. (1973) Wasps: an Account of the Biology and Ntural History of Solitary and Social Wasps. Seatle, University of Washington Press.

Spradbery, J.P. and Maywald, G.F. (1992) The distribution of the European or German wasp, Vespula germanica (F.) (Hymenoptera: Vespidae), in Australia: past, present and future. Australian Journal of Zoology, 40,495-510. 
323 Strassmann, J. (2001) The rarity of multiple mating by females in the social Hymenoptera. Insect Sociaux, 48,1-13.

Villacide, J.M. and Corley, J.C. (2008) Parasitism and dispersal potential of Sirex noctilio: implications for biological control. Agricultural and Forest Entomology, 10,341-345. Villacide, J.M. and Corley, J.C. (2012) Ecological knowledge of the woodwasp Sirex noctilio: tackling the challenge of successful pest management. International Journal of Pest ManagementSpecial Issue, 58,249-256. de la ecología de invasiones en el manejo de plagas. Ecología Austral, 24,154-161. 


\section{$332 \quad$ Figure legends}

333 Fig. 1 Distance flown (mean $\pm \mathrm{SE}$ ) by overwintered and non-overwintered $V$. germanica queens.

334 Non-overwintered queens flew significantly more than overwintered ones (4678 $\pm 443 \mathrm{~m}[n=44]$;

$3351531 \pm 486 \mathrm{~m}[n=35])$. Black circles indicate mean values and bars indicate standard errors.

336 Different lowercase letters above error bars show statistical differences $(P<0.0001)$.

Fig. 2 Distance flown by non-overwintered and overwintered $V$. germanica queens as a function of (A) initial weight (IW) and (B) total wing area (TWA). (A) Distance flown by non-overwintered queens $=-11712+50173 * \operatorname{IW}(P=0.26, n=44) ;$ and distance flown by overwintered queens $=-1990+$ $11643 * \operatorname{IW}(P=0.04, n=35)$

. (B) Distance flown by non-overwintered queens $=17357-12166 *$ TWA $(P=0.54, n=44)$; and distance flown by overwintered queens $(\mathrm{m})=-10791+11912 *$ TWA $(P=$ $0.38, n=35)$. The crosses represent non-overwintered queens and points overwintered ones. These graphs show flight distance with individual predictors for a best visualization. 


\section{$347 \quad$ Figures}

$348 \quad$ Figure 1

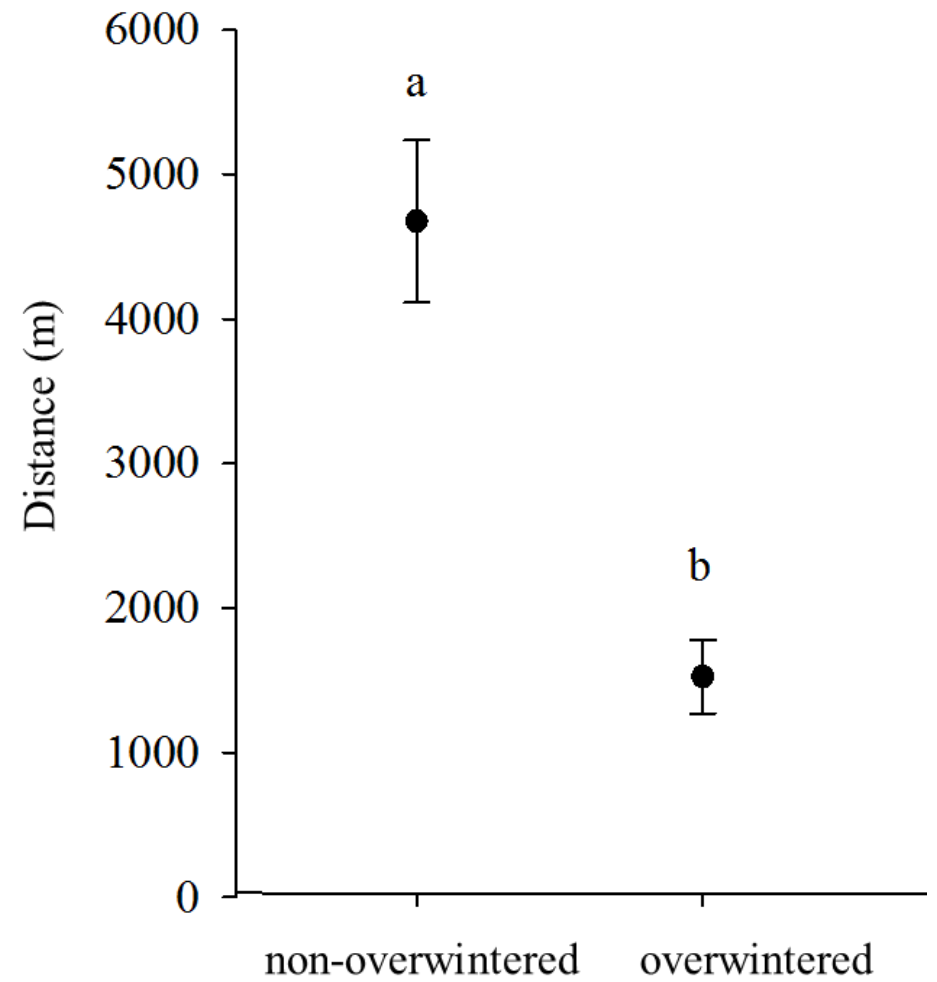

Diapause state of queens 
Figure 2

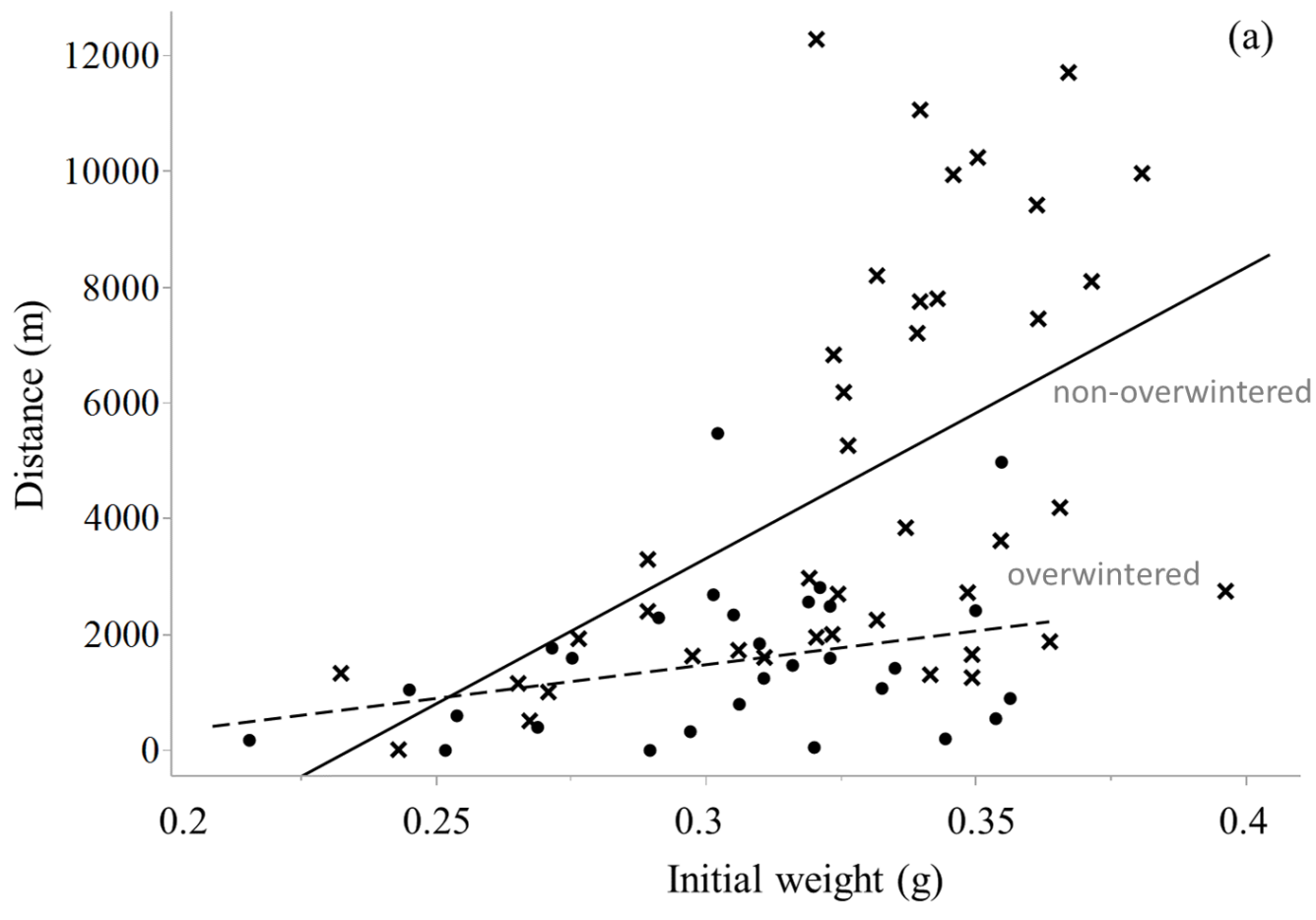

352

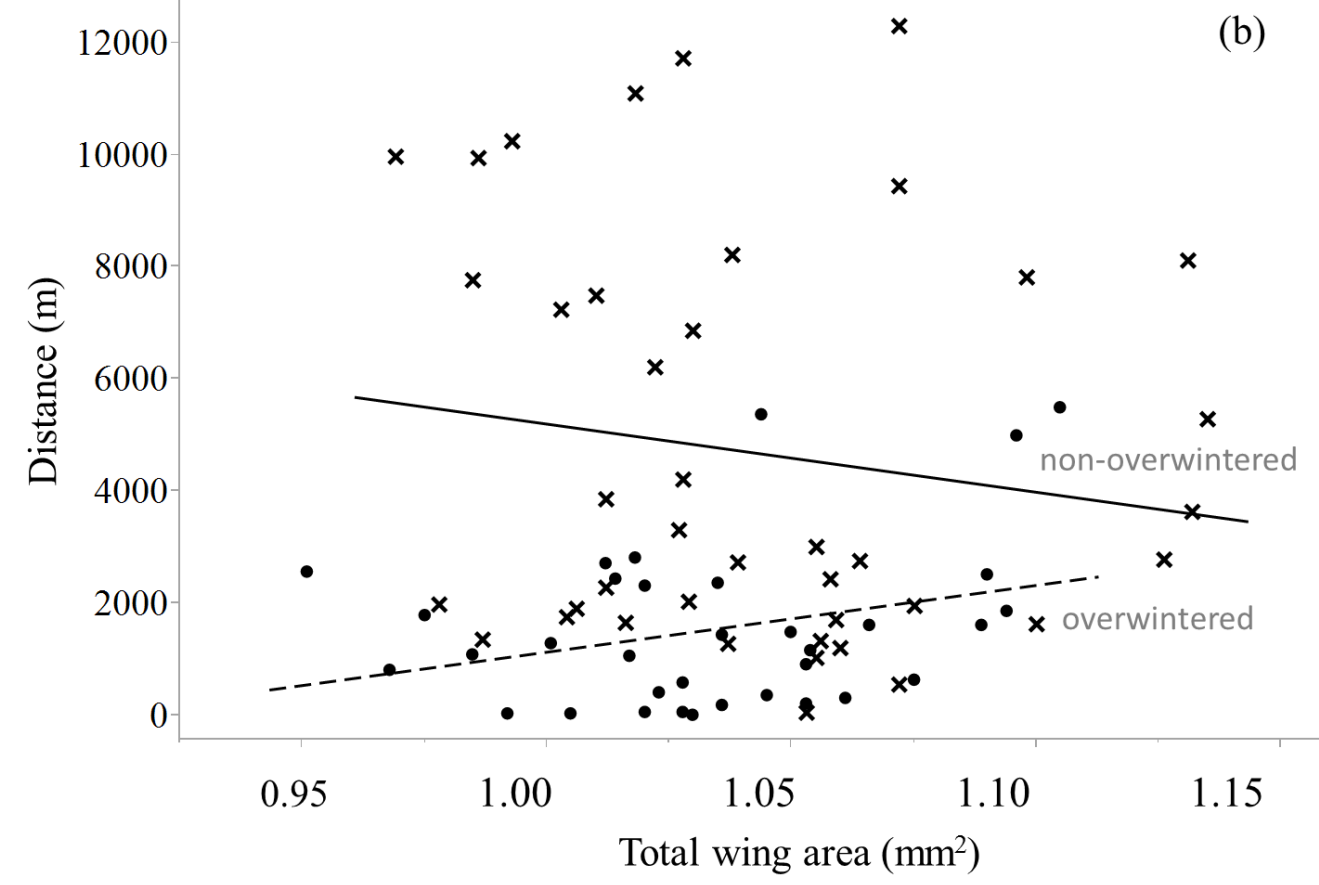

355 Table 1: Comparison of variables (HW, TWA, IW, distance flown) between non-overwintered and overwintered queens of $V$. germanica (mean \pm S.E., $P<0.05$ ). 


\begin{tabular}{lcccl}
\hline Total wing area $\left(\mathrm{mm}^{2}\right)$ & $1.04 \pm 0.01$ & $1.03 \pm 0.01$ & $F_{(1,78)}=0.68$ & 0.4100 \\
Initial weight $(\mathrm{g})$ & $0.33 \pm 0.01$ & $0.30 \pm 0.01$ & $F_{(1,78)}=6.1$ & 0.0161 \\
Distance flown $(\mathrm{m})$ & $4678 \pm 443$ & $1531 \pm 486$ & $F_{(1,78)}=22.9$ & $<0.0001$ \\
$N$ & 44 & 35 & & \\
\hline
\end{tabular}

357

358 Table 2: General linear model of distance flown by $V$. germanica queens as function of diapause

359 status, physiological and morphological (full model: distance HW + IW + D + TWA + two-way

360 interactions). Comparison of model fit parameters supported the following final reduced model:

361 distance $\sim \mathrm{D}+\mathrm{TWA}+\mathrm{IW}+\mathrm{D}:$ TWA + D:IW $(P<0.05)$.

\begin{tabular}{lcccc}
\hline & Estimate & S.E. & Statistic & $P$ \\
\hline Distance & & & & \\
$\quad$ Model constant & 0.38 & 4.85 & $F_{(1,77)}=0.006$ & 0.9400 \\
$\quad$ Diapause status (overwintered) & -1.29 & 0.39 & $F_{(1,77)}=10.91$ & 0.0010 \\
Total wing area $\left(\mathrm{mm}^{2}\right)$ & -8.02 & 4.75 & $F_{(1,77)}=4.17$ & 0.0409 \\
Initial weight (g) & 34.80 & 4.87 & $F_{(1,77)}=18.66$ & $<0.0001$ \\
Diapause status: Total wing area & 12.67 & 4.75 & $F_{(1,77)}=6.58$ & 0.0103 \\
Diapause status: Initial weight & -19.12 & 4.87 & $F_{(1,77)}=10.74$ & 0.0010 \\
\hline
\end{tabular}

